\title{
Aquarius Mission Technical Overview
}

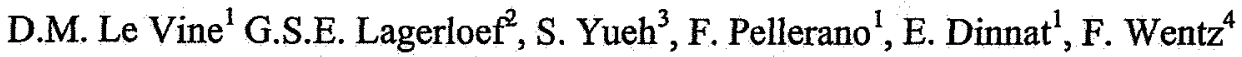 \\ 1. Goddard Space Flight Center, Greenbelt,MD \\ Email: David.M.LeVine@nasa.gov \\ 2. Earth and Space Research, Seattle, WA \\ 3. Jet Propulsion Laboratory, Pasadena, CA \\ 4. Remote Sensing Systems, Santa Rosa, CA
}

\begin{abstract}
Aquarius is an L-band microwave instrument being developed to map the surface salinity field of the oceans from space. It is part of the Aquarius/SAC-D mission, a partnership between the USA (NASA) and Argentina (CONAE) with launch scheduled for early in 2009. The primary science objective of this mission is to monitor the seasonal and interannual variation of the large scale features of the surface salinity field in the open ocean with a spatial resolution of $150 \mathrm{~km}$ and a retrieval accuracy of 0.2 psu globally on a monthly basis.
\end{abstract}

Key words: Microwave Remote Sensing, Ocean Salinity

\section{INTRODUCTION}

Aquarius is a combination active/passive L-band microwave instrument designed to map the surface salinity field of the oceans from space. It will be flown on the Aquarius/SAC-D mission, a partnership between the USA space agency (NASA) and Argentine space agency (CONAE) with launch scheduled for early 2009. CONAE is providing the service platform, SAC-D, the forth spacecraft in the Satelite de Aplicaciones Cientificas (SAC) program and a complement of instruments. In addition, CONAE will provide the data link and mission operations using the facilities at the Mission Operations Center (MOC) at the Cordoba ground station. In addition to Aquarius, NASA will provide the launch, from NASA's Western Test Range at Vandenberg AFB, and the launch vehicle, Delta-II. Aquarius data will be sent from the MOC to the Goddard Space Flight Center for processing where salinity products will be produced. The salinity maps will be distributed to the public and eventually archived at the Physical Oceanography DAAC at the Jet Propulsion Laboratory.

\section{AOUARIUS SCIENCE OBJECTIVES}

The primary objective of the Aquarius instrument is to monitor the seasonal and interannual variation of the large scale features of the surface salinity field in the open ocean. This will provide data to better understand ocean circulation and its impact on climate. For example, salinity is needed to understand the large scale thermohaline circulation, driven by buoyancy, which moves large masses of water and heat around the globe. Salinity also plays an important role in energy exchange between the ocean and atmosphere (for example in the formation of stable buoyant layers at the surface). Salinity is also a surrogate for freshwater flux. In particular, changes in surface salinity reflect changes in freshwater (e.g. evaporation and precipitation, and also river run-off and ice melt). Hence, a map of the global salinity field will also help to better understand the global water cycle and how it is changing. The time and spatial scale of observations needed to improve understanding of these processes are relatively long but the salinity changes are relatively small (tenths of a psu) compared, for example, to processes in the coastal ocean. The goal for the Aquarius instrument is to provide global maps of the sea surface field in the open ocean on a monthly basis with an average accuracy of $0.2 \mathrm{psu}$ and at a spatial resolution of $150 \mathrm{~km}$.

\section{III . THE AQUARIUS INSTRUMENT}

Aquarius is a combination radiometer and scatterometer (radar) operating at $\mathrm{L}$-band $(1.413 \mathrm{GHz}$ for the radiometer and $1.26 \mathrm{GHz}$ for the scatterometer). The prominent feature of this instrument is the antenna, a $2.5-\mathrm{m}$ offset parabolic reflector with three feed horns. The three beams are arranged to image in pushbroom fashion pointed across track (roughly 90 degrees with respect to the spacecraft heading) at incidence angles 25.8, 33.8 and 40.3 degrees with respect to the satellite nadir. The local incidence angles at the surface at beam center are $28.7,37.8$ and 45.6 degrees, respectively. Each feed is shared by both the radiometer and scatterometer. Each feed has a dedicated radiometer; however, there is only one scatterometer which cycles between the three feeds. The resolution of the three beams is approximately the same for the radiometer and scatterometer and ranges at the $3 \mathrm{~dB}$ level from an ellipse of $76 \times 94 \mathrm{~km}$ for the inner beam to $97 \times 157$ $\mathrm{km}$ for the outer beam. Together the three beams provide coverage of a swath of about $390 \mathrm{~km}$.

The radiometers are Dicke radiometers with noise injection for internal calibration (Wilson et al, 2005). The radiometer switching sequence between antenna, Dicke load, and noise diode has been optimized to maximize antenna observations and minimize NEDT. The radiometers measure power at both polarizations and also the sum and difference of the fields (voltages) at the two polarizations from which the third Stoke's parameter can be obtained.

The scatterometer transmits a $1 \mathrm{~ms}$ pulse with a PRF of 100 $\mathrm{Hz}$. This is designed so that the scatterometer pulses and the radiometer observations of the surface are interleaved (an individual radiometer observation is $9 \mathrm{~ms}$ long for a basic period of $10 \mathrm{~ms}$ ). The scatterometer measures power at $\mathrm{VV}$, 
$\mathrm{VH}, \mathrm{HV}, \mathrm{HH}$ and also background noise (no transmit pulse) which is part of calibration. Internal calibration is accomplished with a loop-back circuit which couples a portion of the transmitted power through the receiver chain.

Figure 1 shows Aquarius in its stowed (left) and deployed (right) configuration. The parabolic reflector is deployed with a single fold mechanism and is the largest size that could fit inside the Delta-II launch vehicle fairing. The collar at the junction between Aquarius and the service platform (right) is a sun shield to help with thermal control. The feed structure consists of three feed-OMT assemblies mounted together near the focus of the reflector. The radiometer front end and associated electronics (diplexers that couple with the scatterometer, couplers for the correlated noise diode, etc) are mounted around the OMT and temperature controlled to provide a thermally stable environment for the critical $\mathrm{RF}$ components.

The parameters of the mission and the Aquarius sensor system are listed in Table I. The sensor will be in a sun-synchronous orbit with a $6 \mathrm{pm}$ (ascending) equatorial crossing and altitude of $657 \mathrm{~km}$. This orbit places the spacecraft close to the daynight terminator and the three beams will point to the nighttime side to avoid sun-glint and to provide good coverage of a potential calibration site in the Antarctic. The $390 \mathrm{~km}$ swath will permit complete coverage of the globe in 7 days. The goal is monthly maps and, in order to achieve an accuracy of $0.2 \mathrm{psu}$, averaging is necessary to reduce noise (e.g. Yeuh et al, 2001). An orbit with a 7-day repeat cycle has been selected to assist in the averaging.

\section{SALINITY RETRIEVAL}

The range of salinity to be encountered in the open ocean is on the order of 32-37.5 psu. The associated change in brightness temperature is small but measurable with modern radiometers (Klein and Swift, 1977; Lagerloef et al, 1995), and the window at $1.413 \mathrm{Ghz}$ (L-band) where Aquarius will operate, is very near the peak in sensitivity of brightness temperature to changes in salinity. On the other hand, when actually making the remote sensing measurement from space, there are a number of complicating issues that must be taken into account. For example, surface roughness (e.g. waves) can also cause changes in the observed brightness temperature, and with an order of magnitude comparable to the salinity signature (Camps et al, 2004; Etcheto et al, 2004). It is for this reason, to correct for the contribution of roughness, that Aquarius includes a scatterometer. The scatterometer (backscatter) responds directly to surface roughness, and in the design of Aquarius, the radiometer and scatterometer operate at nearly the same frequency, share the same antenna feed and look at the same pixel with approximately the same footprint. Another issue to be taken into account is Faraday rotation (rotation of the polarization vectors as the radiation propagates from the surface through the ionosphere) which can be significant at L-band (Le Vine and Abraham, 2002).
The inversion from brightness temperature to salinity depends (except at nadir) on polarization. To help correct for this potential source of error, the radiometer in Aquarius includes a polarimetric channel and will use the measured third Stoke's parameter and an algorithm suggested by Yueh (2000) to retrieve the angle of polarization rotation. Finally, the sun is a significant source of radiation at L-band (e.g. Le Vine et al, 2005 ) and to avoid reflection from the ocean surface into the main beam of the antenna, the mission will be in a sunsynchronous orbit near the day-night terminator (i.e. $6 \mathrm{am} / 6$ $\mathrm{pm}$ equatorial crossing) with the antenna beams pointing toward the night time side of the orbit. Finally, the response to changes in salinity depends on incidence angle (the angle relative to the local normal to the surface). With large antenna footprints such as are being used with Aquarius, changes in incidence angle across the footprint can be important (Dinnat and Le Vine, 2006). Figure 2 is an example showing the difference between the brightness temperature at boresight and the value obtained by the actual antenna (i.e. after integration over the antenna pattern). As a consequence, careful attention needs to be given to the antenna pattern correction. One promising possibility is to use a regression derived from the observations in which a linear combination of the observed values are used to approximate the value at boresight or a related parameter (e.g. the equivalent TB that yields the average SSS over the footprint).

\section{$\mathrm{V}$. REFERENCES}

1. Camps, A.; Font, J.; Vall-1lossera, M.; et al., "The WISE 2000 and 2001 field experiments in support of the SMOS mission: sea surface L-band brightness temperature observations and their application to sea surface salinity retrieval”, IEEE Trans. Geosci. Remote Sens., 42 (\#4),804823, 2004.

2. Dinnat, E.P. and D.M. Le Vine, "Effects of the Antenna Aperture on Remote Sensing of Sea Surface Salinity at L-band", Proc. MicroRad06, Feb28-Mar3, San Juan, Puerto Rico, 2006.

3. Etcheto, J., E. innat, J. Boutin, A. Camps, J. iller, S. Contardo, J. Wesson, J.Font and D.Long, "Wind speed effect on L-band brightness temperature inferred from EuroSTARRS and WISE2001 field experiments", IEEE Trans. Geosci. \& Remote Sens., vol. 42, no. 10, Oct, 2004.

4. Klein, L.A. and C.T. Swif, "An impro0ved model for the dielectric constant fo sea water at microwave frequencies", IEEE Trans. Antennas and Propag., AP-25, 104-111, 1977.

5. Lagerloef, G.S.E, C. Swift, D. Le Vine, 1995, Sea surface salinity: The next remote sensing challenge, Oceanogr. 8, 44-50.

6. Le Vine, D.M. and S. Abraham, "The effect of the ionosphere on remotes ensing of sea surface salinity from space: Absorption and emission at L-band", IEEE Trans. Geosci. Remote Sens., 40 (\#4), 771 $782,2002$.

7. Le Vine, D.M., S. Abraham, F. Wentz, G.S.E. Lagerloef, "Impact of the Sun on Remote Sensing of Sea Surface Salinity from Space", Proc. Internat. Geosci. \& Remote Sens. Symp., IGARSS05, Seoul Korea, July, 2005. .

8. Wilson, W. J., Tanner, A., Pellerano, F., and Horgan, K. Ultrastable Radiometers for Future Sea Surface Salinity Missions, Jet Propulsion Laboratory Report D-31794, April 2005.

9. Yueh, S.H., "Estimates of Faraday Rotation with Passive Microwave Polarimetry for Microwave Remote Sensing of Earth Surfaces", IEEE Trans. Geosci Remote Sens., Vol 38 (\#5), pp 2434-24-38, 2000.

10. Yueh, S.H., R. West, W.J. Wilson, F.K. Li, E.G. Njoku, and Y. RahmatSamii, "Error Sources and Feasibility for Microwave Remote Sensing of Ocean Surface Salinity", IEEE Trans. Geosci and Remote Sensing, Vol 39, \#5, pp 1049-1059, May, 2001. 

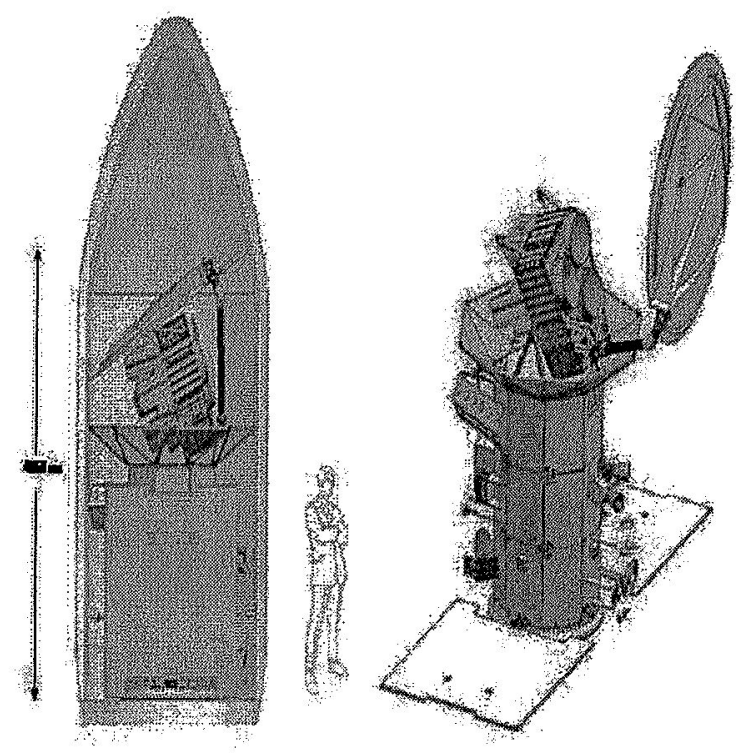

Figure 1: Aquarius in the stowed configuration (left) and deployed (right). The deployed configuration shows Aquarius mounted on the SAC-D spacecraft.
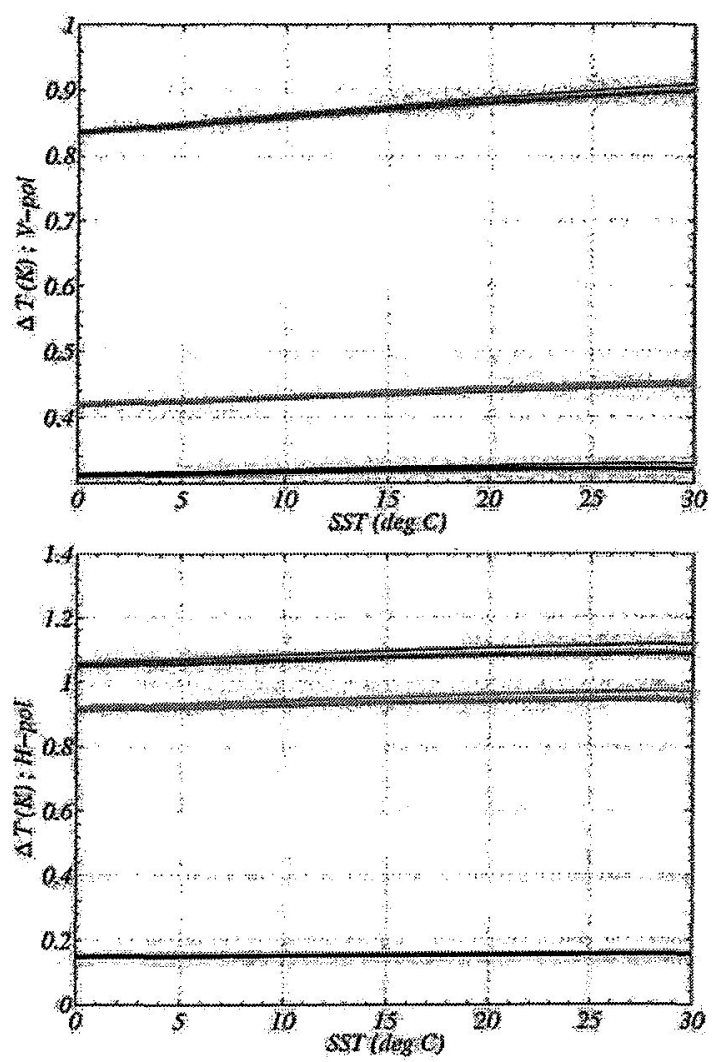

Figure 2: The difference between the brightness temperature obtained by the actual antenna (i.e. after integrated over the antenna pattern) and the value at boresight. Results at the top are for vertical polarization and at the bottom for horizontal polarization. The three curves are for the three beams: 25.8 (red), 33.8 (green) and 40.3 (blue). There are two curves for each case for SSS of 31 psu and $38 \mathrm{psu}$.

TABLE I

Parameters of the Aquarius Mission

\begin{tabular}{|ll|lc|}
\hline Orbit & & Antenna & \\
\hline Altitude & $657 \mathrm{~km}$ & Main Reflector & $2.5 \mathrm{~m}$ offset \\
Sun-synchronous & $6 \mathrm{pm}$ ascending & Beam look angles (deg) & $25.8,33.8,40.3$ \\
Inclination & $98 \mathrm{deg}$ & Local incidence (deg) & $28.7,37.8,45.6$ \\
Coverage & 7 days global & Res (eff radius) & $42,50,61 \mathrm{~km}$ \\
& & Swath & $390 \mathrm{~km}$ \\
& & & \\
\hline Radiometer & & Scatterometer & \\
\hline Frequency & $1.413 \mathrm{GHz}$ & Frequency & $1.26 \mathrm{GHz}$ \\
Polarization & Polarimetric & Polarization & $\mathrm{HH}, \mathrm{VH}, \mathrm{HV}, \mathrm{VV}$ \\
Sample time & $10 \mathrm{~ms}$ & PRF & $100 \mathrm{~Hz}$ \\
Integration time/sample & $9 \mathrm{~ms}$ & Pulse width & $0.98 \mathrm{~ms}$ \\
NEDT (5.76 seconds) & $0.06 \mathrm{~K}$ & Calibration & $0.1 \mathrm{~dB}$ \\
Calibration Stability & $0.13 \mathrm{~K}$ & & \\
& & & \\
\hline
\end{tabular}

